\title{
Comparison of Weak Load Bus Detection using LQP_LT Index with PV and QV Analysis of PSS/E
}

\author{
Renuga Verayiah ${ }^{1}$, Azah Mohamed ${ }^{2}$ \\ ${ }^{1}$ Electrical Power Engineering Department, Universiti Tenaga Nasional, Selangor, Malaysia \\ ${ }^{2}$ Centre for Integrated Engineering Systems and Advanced Technologies, Universiti Kebangsaan Malaysia, Selangor, \\ Malaysia
}

\begin{tabular}{l} 
Article Info \\
\hline Article history: \\
Received Apr 29, 2018 \\
Revised Jun 20, 2018 \\
Accepted Jul 11, 2018 \\
\hline
\end{tabular}

\section{Keywords:}

Voltage instability $\mathrm{Pv}$ and qv analysis

Reactive power tracing index

\begin{abstract}
Identification of weak load buses which contributes to voltage instability problem is crucial in order for an appropriate mitigation action to be executed. The current power system transmission is not only stressed to deliver high load demand at the receiving end but also facing new challenges brought by the penetratrion of renewable energy sources. This new scenario requires power system operation and analysis to be robust and fast in detecting the accurate weak load bus for correction action. Due to this, many online indices to detect weak load bus during power system contingency have been developed. Nevertheless, LQP_LT is of the latest index developed which ultimately has the reactive power tracing capability for weak load bus detection and generate priority ranking list of the weak load buses. This index was tested on IEEE 14 bus test system for different contingency scenarios. The results obtained from the LQP_LT index is compared and validated with the PV and QV analyses obtained using industrial graded PSS/E software. It was concluded that the LQP_LT index is found to be robust, efficient and need less computation time as compared to the execution of voltage stability analysis using the PSS/E Tool.
\end{abstract}

Copyright $@ 2018$ Institute of Advanced Engineering and Science. All rights reserved.

\section{Corresponding Author:}

Renuga Verayiah,

Electrical Power Engineering Department,

Universiti Tenaga Nasional,

Selangor, Malaysia.

Email: renuga@uniten.edu.my

\section{INTRODUCTION}

Power system voltage stability has always been a vital aspect in operating a stable and reliable grid system [1]. Many major blackout occurrences due to power system instability aids to the continues research and analysis in the voltage stability study [2,3]. Originally, angle stability was the main concern to power utilities. But, in the previous two decades power systems have been operating under more stressed conditions due to several factors. Limitations to install new generating plants due the environmental pressures and economical reason caused the transmission lines to operate near the loading limits in order to cater for the electricity power consumption in heavy load areas. In addition, the system loading pattern due to deregulation in the electricity market, the growing use of induction machines and large penetration of renewable energy sources in distribution systems have made local coordination control system to appear more complex.

A voltage instability phenomenon takes place when the receiving end voltage decreases well below its normal operating point. The voltage decline in voltage instability framework occurs when the combined generation and transmission system is unable to provide or meet the power demanded by the loads. The imbalance between the generation power and demand power can be due to system outage or limitations in reactive power sources or a combination of both. Severe voltage instability may lead to voltage collapse 
which is the process by which the sequence of events accompanying voltage instability leads to a blackout or abnormally low voltages in a significant portion of a power system [4].

Several methods have been developed to identify the load shedding locations in which the recent methods are based on sensitivity analysis and voltage stability index calculation. Sensitivity analysis can be classified into P-V and V-Q analyses. Due to the nonlinear nature of power system operation, the magnitude of the sensitivities for different system conditions does not provide a direct measure of the relative degree of voltage stability. The sensitivity method is considered time-consuming because it requires repetitive power flow solutions and therefore incurs high computational time when solving large networks. Another method for identifying load shedding locations is by identifying critical lines of critical buses using proximity indicators based on voltage stability index [5-8]. The proximity indicators could identify how far a power system is from its voltage collapse point [9]. Different proximity indicators have different controllable parameters and are defined through a simple function. Due to that, every proximity indicator may perform differently based on the complexity of the cases involved and yields different critical lines or buses. Examples of voltage stability indices that have been tested on the IEEE 14 bus test system are the Lij index [9], Fast Voltage Stability Index (FVSI) [10] and Voltage Collapse Proximity Indicators (VCPI) [5]. All these indices have indicated that bus 14 is the weakest bus for numerous contingency analyses performed and the ranking results for other buses in the test system has some variations as well.

This paper presents the performance of LQP_LT index in providing fast and accurate priority ranking list of weak load bus for contingency scenarios in IEEE 14 bus test system. The results obtained are compared and validated using PV and QV analysis derived from an industrial graded PSS/E software.

\section{IEEE 14 BUS TEST SYSTEM MODEL AND LQP_LT INDEX ALGORITHM}

The test systems used for the weak load bus identification are the standard IEEE 14 bus system. The IEEE 14 bus test system consists of 14 buses with 5 PV buses, 10 PQ buses and 20 branches. Figure 1 shows the single line diagram of the IEEE 14 bus system. Two load conditions have been considered in the analysis, which are base case and heavily loaded conditions. For the LQP_LT computation, the algorithm is developed using MATLAB and integrated with the power flow analysis simulation in MATPOWER.

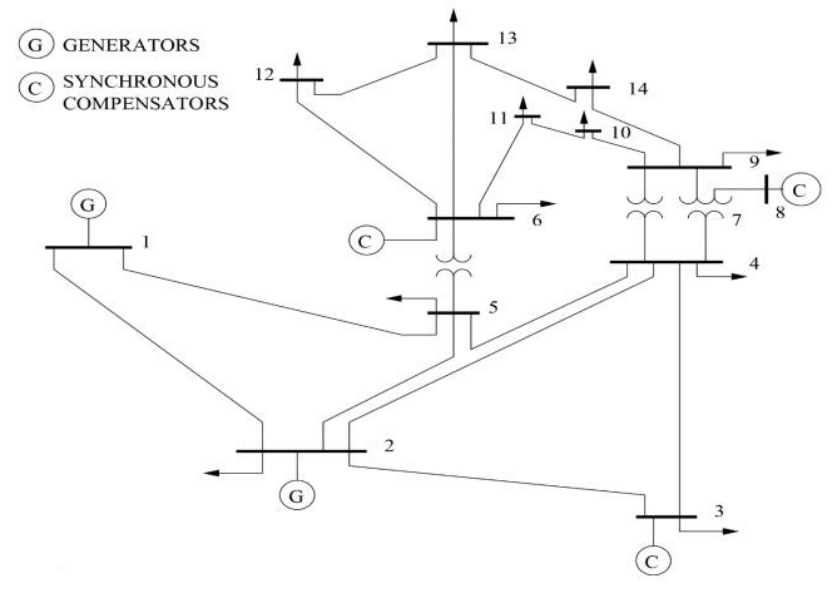

Figure 1. Single-line diagram of the IEEE 14 bus system [11]

\subsection{Formulation of LQP_LT Index}

LQP_LT index is capable of tracing the reactive power contribution of each load bus into the system lines. The derivation of LQP_LT index is presented in detail in [12-14]. The formulation of LQP_LT, which is the total traced LQP_LT of line $l-m$ due to the $i$-th load of reactive power, $Q_{L i}$ is written as follows,

$$
L Q P_{-} L T_{l m}=4\left(\frac{X_{i j}}{V_{i}^{2}}\right)\left(\left[\sum_{i=1}^{L n} Q_{l m}^{L i}\right]+\frac{X_{i j} P_{i}^{2}}{V_{i}^{2}}\right)
$$

where, 
Ln : $\quad$ number of loads or reactive power sinks in the system

$Q_{l m}^{L i} \quad: \quad$ receiving end reactive power contributed by the i-th load or reactive sink in line $l-m$

$x_{l m}^{i} \quad: \quad$ receiving end reactive power fraction in line $l-m$

$X \quad: \quad$ line reactance

$V_{i} \quad: \quad$ sending end voltage in p.u.

$P_{i} \quad: \quad$ sending end real power, and

$$
Q_{l m}^{L i}=x_{l m}^{i} \cdot Q_{L i}
$$

The computation of LQP_LT index for an individual load bus contribution has a range of value between 0 to 1.0. The significance of tracing reactive power flow in every line due to a load will in fact indicate which load buses in the system that cause highest congestion level to a particular transmission line. If the index value is close to 1.0 , it indicates that the particular load bus is contributing to the insufficient reactive power flow in the particular line, thus leading the system to voltage instability issue and subsequently voltage collapse.

\subsection{LQP LT Algorithm in MATLAB}

A reactive power tracing algorithm is developed in MATLAB to calculate the reactive power tracing index, LQP_LT and it can automatically perform the ranking of the LQP_LT index for identifying the weak buses in a power system. The flowchart in Figure 2 shows the implementation steps for the LQP_LT algorithm. The derivation involved in each step of the flowchart can be found in [12-14].

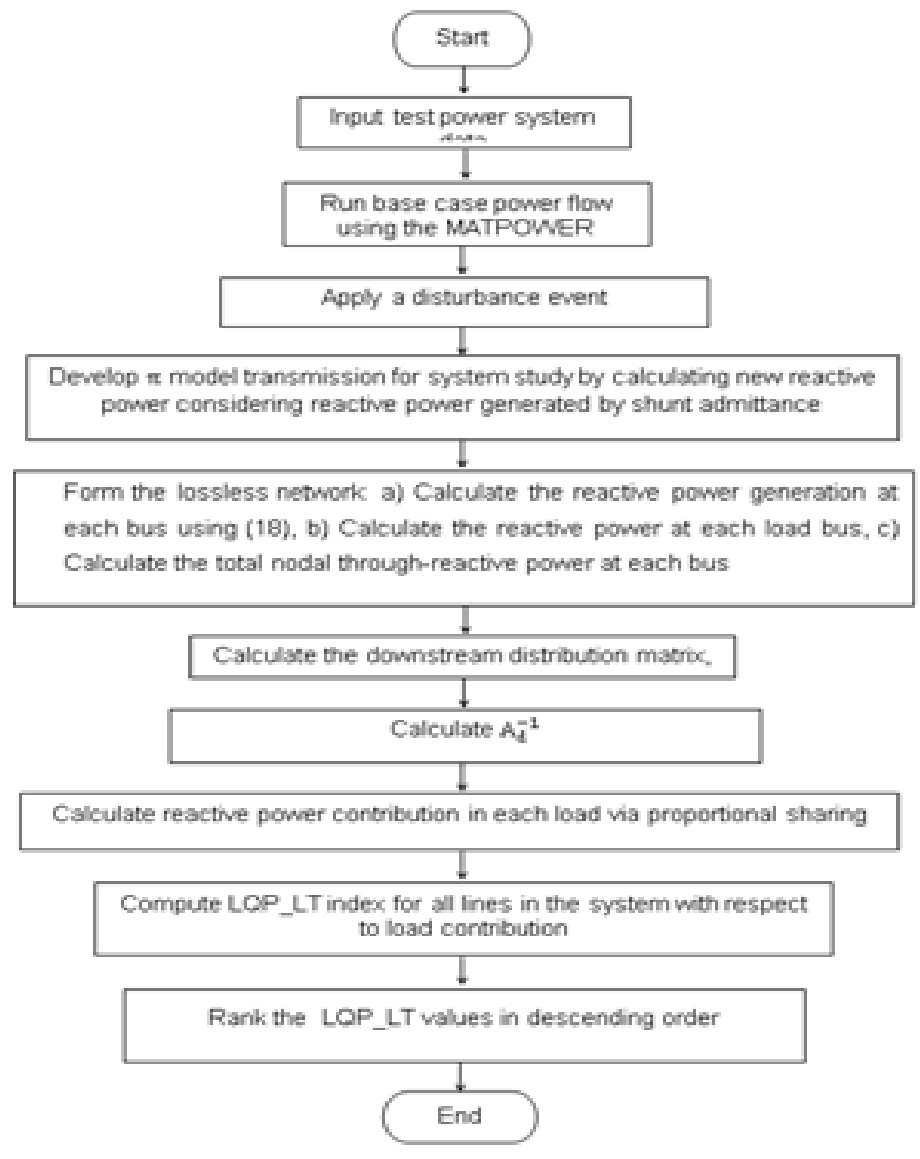

Figure 2. Implementation steps of LQP_LT index computation

\section{1. $\quad$ LQP_LT Computation for Base Case Condition}

LQP_LT of an individual line due to a power fraction contribution of an individual load, with notation, $L Q P_{-} L T_{l-m(\text { load })}$ is used and the LQP_LT computation results of the IEEE 14 bus system is shown 
in Table 1 for the base case without any increase in load. Table 2 shows the first five highest $\sum_{L o a d} L Q P \_L T$ index values obtained for the IEEE 14 bus. From Table 2, the five buses with high $\sum_{L o a d} L Q P \_L T$ index values for the 14 bus system are bus 9 followed by bus 14, bus 10, bus 13 and bus 6 . This indicates that the load at bus 9 exerts more reactive power flow in order to keep the bus voltage at its nominal value. Close monitoring would be needed at these buses as further increase in load demand may cause insufficient reactive power to maintain the bus voltage close to its nominal value.

Table 1. Results for LQP_LT index computation for base case in IEEE 14 bus system

\begin{tabular}{|c|c|c|c|c|c|c|c|c|c|c|c|c|}
\hline \multirow[b]{2}{*}{ From Bus } & \multirow[b]{2}{*}{ To Bus } & \multicolumn{10}{|c|}{ LQP LT Computed due to Individual Load Buses } & \multirow{2}{*}{$\begin{array}{c}\text { Total } \\
\text { Summation, } \\
\sum_{\text {lines }} L Q P L T\end{array}$} \\
\hline & & 2 & 3 & 5 & 6 & 9 & 10 & 11 & 12 & 13 & 14 & \\
\hline 2 & 1 & 0.690 & 0.0198 & 0.0204 & 0.0212 & 0.0198 & 0.0205 & 0.0201 & 0.0201 & 0.0209 & 0.0202 & 0.2024 \\
\hline 1 & 5 & $0.0 p 81$ & 0.0681 & 0.0704 & 0.0732 & 0.0681 & 0.0700 & 0.0693 & 0.0692 & 0.0720 & 0.0697 & 0.6981 \\
\hline 2 & 3 & 0.0425 & 0.0463 & 0.0426 & 0.0427 & 0.0425 & 0.0426 & 0.0425 & 0.0425 & 0.0426 & 0.0425 & 0.4292 \\
\hline 4 & 2 & 0.0691 & 0.0276 & 0.0276 & 0.0277 & 0.0276 & 0.0276 & 0.0276 & 0.0276 & 0.0277 & 0.0276 & 0.2778 \\
\hline 2 & 5 & 0.0148 & 0.0148 & 0.0166 & 0.0188 & 0.0148 & 0.0163 & 0.0158 & 0.0157 & 0.0179 & 0.0161 & 0.1615 \\
\hline 3 & 4 & $0.0 p 20$ & 0.0014 & 0.0042 & 0.0076 & 0,0026 & 0.0039 & 0.0029 & 0.0027 & 0.0062 & 0.0036 & 0.0373 \\
\hline 4 & 5 & 0.0017 & 0.0017 & 0.0033 & 0.0053 & 0.0017 & 0.0030 & 0.0025 & e.0025 & 0.0045 & 0.0028 & 0.0290 \\
\hline 7 & 4 & 0.0083 & 0.0078 & 0.0101 & 0. & \multirow{3}{*}{\multicolumn{3}{|c|}{$\begin{array}{c}L Q P_{-} L T_{l-m(\text { load })}= \\
\text { LQP_LT } T_{3-6(5)}=0.0438\end{array}$}} & 039 & 0.0117 & 0.0095 & 0.0966 \\
\hline 4 & 9 & 0.0066 & 0.0266 & 0.0266 & 0. & & & & 266 & 0.0266 & 0.0281 & 0.2789 \\
\hline 5 & 6 & 0.0438 & 0.0438 & 0.0438 & & & & & 511 & 0.0703 & 0,0548 & 0.5379 \\
\hline 6 & 11 & 0.0005 & 0.0005 & 0.0005 & 0.0005 & 0.0005 & 0.0204 & 0.0135 & 0.0005 & 0.0005 & 0.0005 & 0.0377 \\
\hline 6 & 12 & 0.0013 & 0.0013 & 0.0013 & 0.0013 & 0.0013 & 0.0013 & 0.0013 & 0.0161 & 0.0072 & 0.0037 & 0.0359 \\
\hline 6 & 13 & 0.0016 & 0.0016 & 0.0016 & 0.0016 & 0.0016 & 0.0016 & 0.0016 & 0.0016 & 0.0260 & 0.0118 & 0.0509 \\
\hline 8 & 7 & 0.0012 & 0.0008 & 0.0027 & 0.0049 & 0.1049 & 0.0214 & 0.0018 & 0.0017 & 0.0040 & 0.0184 & 0.1617 \\
\hline 7 & 9 & 0.0042 & 0.0042 & 0.0042 & 0.0042 & 0.0704 & 0.0163 & 0.0042 & 0.0042 & 0.0042 & 0.0145 & 0.1303 \\
\hline 9 & 10 & 0.0001 & 0.0001 & 0.0001 & 0.0001 & 0.0001 & 0.0097 & 0.0001 & 0.0001 & 0.0001 & 0.0001 & 0.0107 \\
\hline 9 & 14 & 0.0027 & 0.0027 & 0.0027 & 0.0027 & 0.0027 & 0.0027 & 0.0027 & 0.0027 & 0.0027 & 0.0289 & 0.0530 \\
\hline 11 & 10 & 0.0001 & 0.0001 & 0.0001 & 0.0001 & 0.0001 & 0.0198 & 0.0001 & 0.0001 & 0.0001 & 0.0001 & 0.0206 \\
\hline 12 & 13 & 0.0000 & 0.0000 & 0.0000 & 0.0000 & 0.0000 & 0.0000 & 0.0000 & 0.0000 & 0.0048 & 0.0020 & 0.0071 \\
\hline 13 & 14 & 0.0010 & 0.0010 & 0.0010 & 0.0010 & 0.0010 & 0.0010 & 0.0010 & 0.0010 & 0.0010 & 0.0326 & 0.0419 \\
\hline \multicolumn{2}{|c|}{ Maximum Traced } & 0.6681 & 0.0681 & 0.0704 & 0.0780 & 0.1049 & 0.0700 & 0.0693 & 0.0692 & 0.0720 & 0.0697 & \\
\hline \multicolumn{2}{|c|}{ Total Summation, $\sum_{\text {load }} L Q P \_L T$} & 0.2692 & 0.2701 & 0.2798 & 0.3303 & 0.4485 & 0.3725 & 0.2946 & 0.2948 & 0.3510 & 0.3877 & \\
\hline
\end{tabular}

Table 2. Five highest LQP_LT index values for base case condition

\begin{tabular}{cccccc}
\hline Load Bus & 9 & 14 & 10 & 13 & 6 \\
\hline$\sum_{\text {Load }} L Q P_{-} L T$ & 0.4485 & 0.3877 & 0.3725 & 0.3509 & 0.3304 \\
\hline
\end{tabular}

\subsection{LQP_LT Computation for Heavily Loaded System}

To test the effectiveness of LQP_LT index in identifying the weak load buses in the IEEE 14 bus, the loads are increased in stages until the power flow diverges. For the IEEE 14 bus system, the power flow diverges when the loading at all the load buses are increased up to $57 \%$ or by a loading factor of 2.37 from the base case load. Figure 3 show the voltage profile for all the buses when the load is increased gradually as per the loading factor shown for the IEEE 14 bus system. It can be seen from the figure that the bus voltages decrease as the loading is increased gradually. This is mainly due to insufficient reactive power margin in the system in order to support the voltages as more real power is transferred in the system. For the IEEE 14 bus system, voltage collapse is said to occur at bus 14 with the lowest voltage recorded at 0.697 p.u. The ranking results of LQP_LT index summation by the load buses, $\sum_{\text {Load }} L Q P \_L T$ is shown in Figure 4 . The results are ranked from the highest to the lowest $\sum_{L o a d} L Q P \_L T$ to indicate the priority for any corrective or preventive actions. The highest ranked bus indicates it is a weak bus. The highest $\sum_{L o a d} L Q P \_L T$ index for the load bus is obtained at bus 9 followed by bus 14, 10, 13 and bus 6 , and these buses are the weak load buses that have contributed to high congestion level in the system. Precisely, bus 9 will be the most suitable location for any corrective and preventive action by the system operator. It can be concluded that bus 9 , followed by bus 14 , bus 10 , bus 13 and bus 6 will be the suitable locations for load shedding purposes as well. Besides that, actions such as shunt element or static VAR compensator (SVC) installation should be performed at these weak load buses for the purpose of providing reactive power support. 


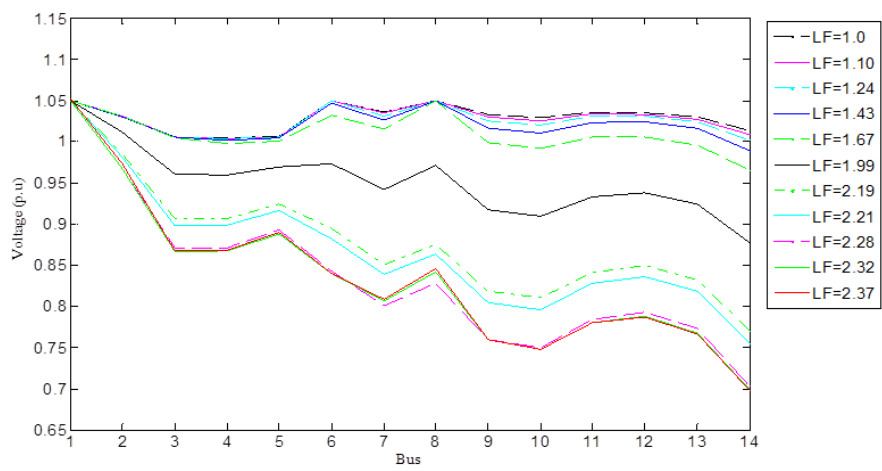

Figure 3. Voltage profile due to gradual load increase in the IEEE 14 bus system

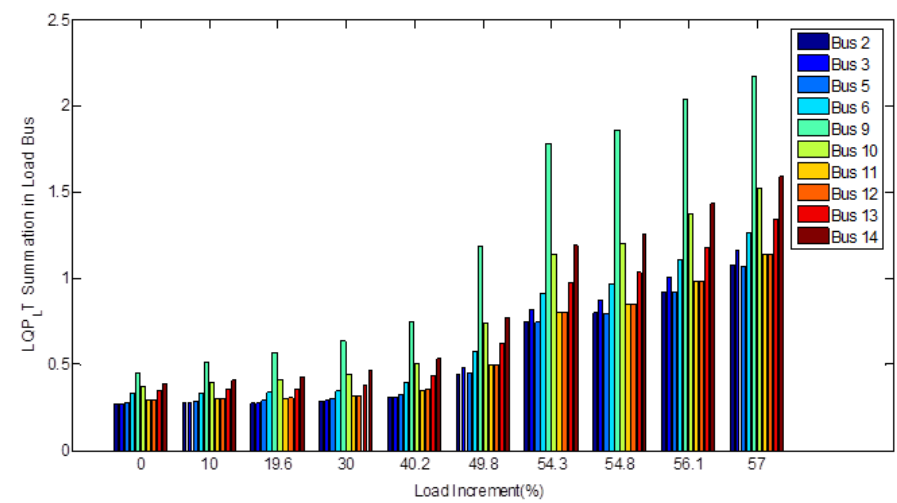

Figure 4. LQP_LT index, $\sum_{\text {Load }} L Q P \_L T$, computed for load buses with loading increment in the IEEE 14 bus system

\subsection{PV Analysis for Weak Load Bus}

In PSS/E tool, the PV curves are generated by selecting two subsystems where the power transfer between the subsystems is incremented in a defined step size for a series of AC power calculations while the bus voltages, generator outputs and the branch flows of the system are monitored. When the bus voltages are plotted as a function of the incremental power transfer, the PV curves are obtained. One of the subsystems in the study must be defined as the study (source) subsystem and another as the opposing (sink) subsystem. The power flows from the study subsystem to the opposing subsystem. In this simulation, the PV analysis is performed for the subsystem created as shown in Table 3. The incremental power transfer from base case until the maximum loading takes place from the source subsystem to the sink subsystem as shown in Table 3.

Table 3. Source and sink buses in the 14 bus test system

\begin{tabular}{cc}
\hline Source Bus & Sink Bus \\
\hline 2 & 1 \\
3 & 6 \\
4 & 7 \\
5 & 8 \\
& 9 \\
& 10 \\
& 11 \\
& 12 \\
& 13 \\
& 14 \\
\hline
\end{tabular}

Figure 5 shows the PV curve obtained for the monitored sink buses for the incremental load demand. The PV curve obtained shows that bus 14 has the lowest voltage, followed by bus 13 , bus 10 , bus 12 , bus 9 and bus 6 . At base case, bus 14 recorded a voltage value of 0.913 p.u for a load demand value of 14.9 MW. When a maximum real power of $62.6 \mathrm{MW}$ is transferred, the voltage reading at bus 14 declined 
towards voltage collapse with a voltage value recorded at 0.560 p.u. This shows that only a maximum of 62.6 MW could be transferred for the load at bus 14 in the system. Bus 7 is considered as the strongest load bus because it has the highest voltage value of 0.699 p.u. when an incremental real power of $77.5 \mathrm{MW}$ is transferred.

\subsection{QV Analysis for Weak Load Bus}

The next analysis performed is the QV analysis for the IEEE 14 bus system. The analysis is carried out to analyse and evaluate how the variation in reactive power affects the load bus voltages in the system. Table 4 shows the reactive power margin recorded for all the buses obtained from the QV curves for the IEEE 14 bus system. The QV curve is plotted for the load bus which has the least reactive power margin.

Table 4. Reactive power margin recorded for the IEEE 14 bus system

\begin{tabular}{ccc}
\hline Bus & Voltage (p.u) & Reactive Power, Q (MVAR) \\
\hline 2 & 0.540 & -410.44 \\
3 & 0.5 & -114.46 \\
4 & 0.5 & -214.26 \\
5 & 0.5 & -234.85 \\
6 & 0.5 & $\mathbf{- 6 2 . 3 2}$ \\
7 & 0.5 & -97.41 \\
8 & 0.5 & -83.60 \\
9 & 0.5 & $\mathbf{- 5 0 . 3 0}$ \\
10 & 0.5 & $\mathbf{- 5 1 . 8 8}$ \\
11 & 0.5 & -64.36 \\
12 & 0.5 & -67.83 \\
13 & 0.5 & $\mathbf{- 6 2 . 5 9}$ \\
14 & 0.5 & $\mathbf{- 4 9 . 9 6}$ \\
\hline
\end{tabular}
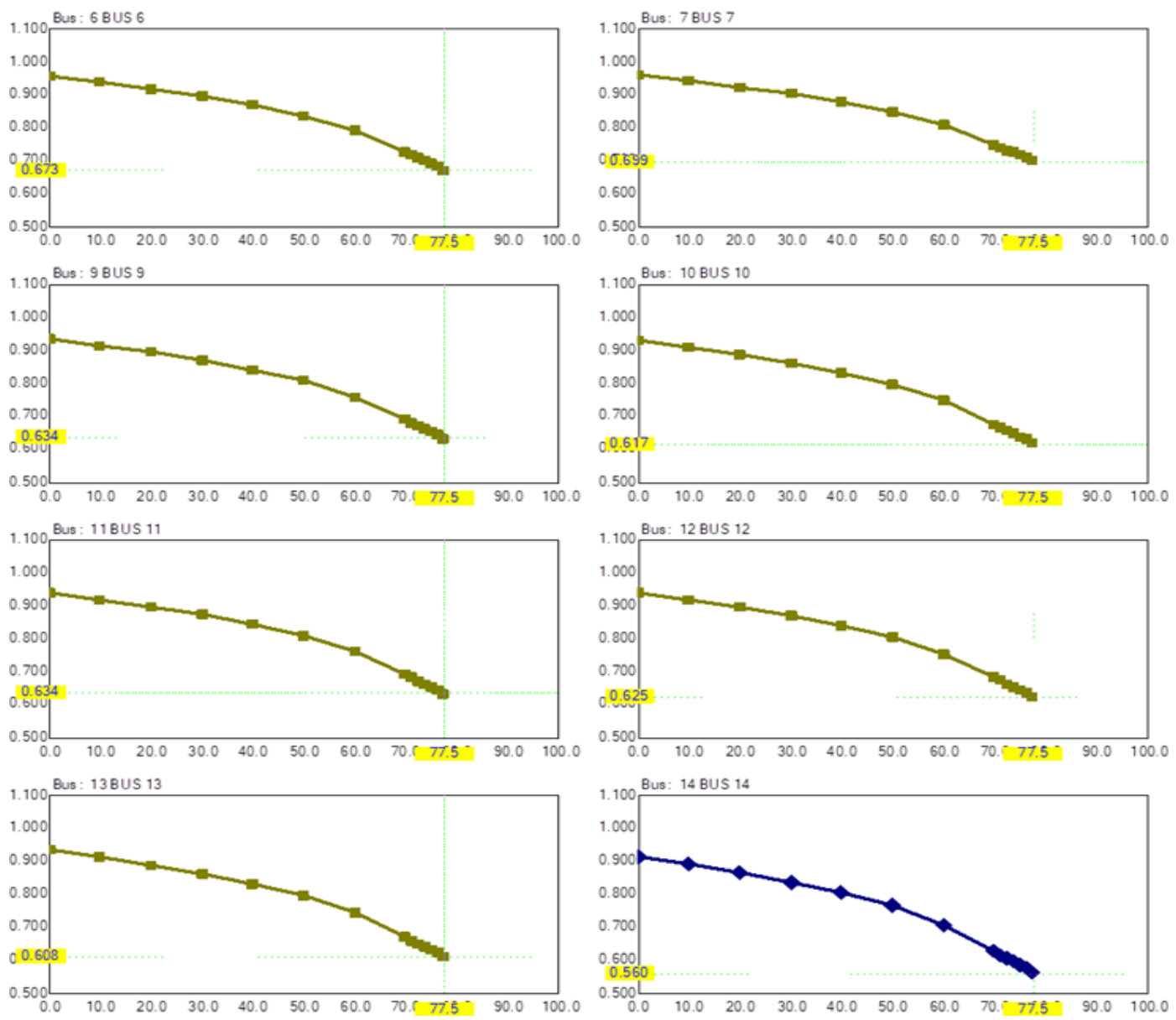

Figure 5. PV curves for the IEEE 14 bus system 
Figure 6 shows the QV curve obtained for load bus 14 for the 14 bus system. From the QV curve obtained, bus 14 followed by bus 9 , bus 10 , bus 13 and bus 6 have the least reactive power margin as compared to other buses in the IEEE 14 bus system. Bus 14 has the least reactive power margin recorded at 49.96 MVar.

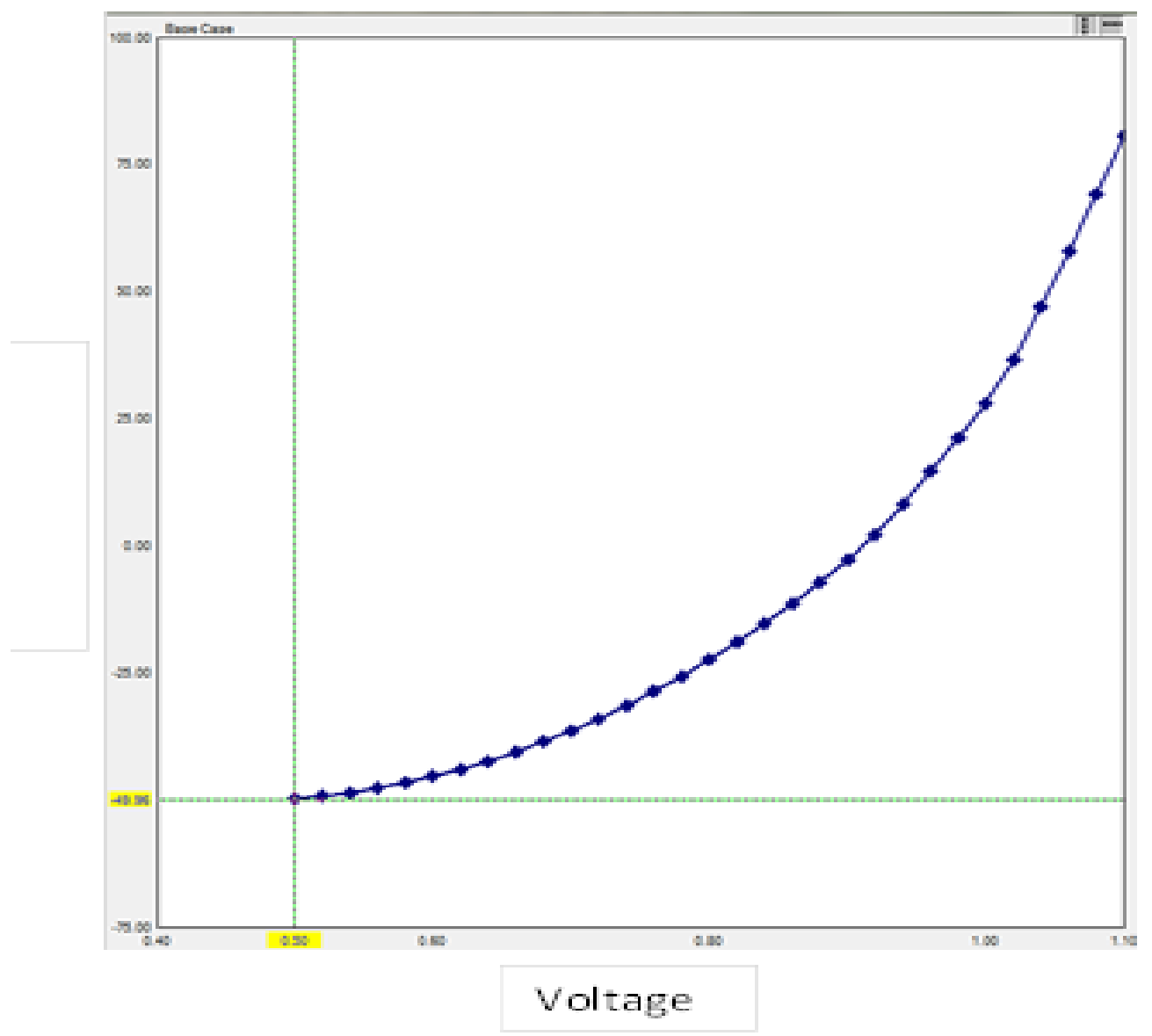

Figure 6. QV curve for bus 14 of the IEEE 14 bus system

\subsection{Summary on Comparison between LQP_LT Index and PV and QV Analysis using \\ PSS/E Tool}

A key element of voltage stability studies is the determination of critical bus or a cluster of critical buses. These buses can then be monitored as they will invariably form the electrical centroid of a voltage collapse. Simulations via PSS/E for localized heavy loading scenarios on the IEEE 14 bus were performed to evaluate and identify the weak areas. Analyses performed via PV and QV curves have narrowed down to identification of the weak area and weak buses in the test system, thus monitoring of these buses become crucial. Based on the Western Electricity Coordinating Council guideline for voltage stability criteria and under voltage load shedding strategy [15], a critical bus exhibits the following criteria for any worst contingency:

a) In a radial transmission system consisting of a generator serving several loads along a transmission line, the critical bus or weak bus is generally located electrically and physically furthest away from the generator. For the simulations performed on the IEEE 14 bus system, the identified weak buses which are bus 14, 9, 10, 6 and 13 are located far away from the generator buses. These identified weak buses via PV analysis are in agreement with the weak buses obtained via LQP_LT tracing index.

b) The industry experiences revealed that the weakest buses or cluster of weak buses are generally located in locations with reactive power deficiencies. The results obtained from QV analysis via PSS/E on the IEEE 14 bus system have indicated that those weak buses have insufficient reactive power. It was clearly shown that the weak buses identified by QV analysis are identical with the weak buses obtained via LQP_LT tracing index. 
c) The weakest bus indicates the voltage collapse point on the QV curve. The QV analysis results obtained from the PSS/E simulations for the IEEE 14 bus system shows that weak bus 14 is the voltage collapse point on the QV plot.

d) The weak buses in the power system have the lowest reactive power margin. In the simulations of the IEEE 14 bus system, bus 14, bus 9, bus 10, bus 13 and bus 6 are among the buses with low reactive power margin assessed from the QV curve.

e) The weak buses have high percentage change in voltage from the PV curve. From the PV analysis performed via PSS/E, bus 14 has indicated an abrupt change in voltage with respect to incremental power transfer, thus resulted in high percentage change in voltage.

\section{CONCLUSION}

The LQP_LT index which incorporates the power tracing capability is a new index for accurate weak load bus detection in a critical power system. This index is tested on IEEE14 bus system for contingency cases, and it has provided a useful ranking list of weak load buses. Similar contingencies were also simulated using the industrial graded Power System Simulator Software, PSS/E. In the simulation using $\mathrm{PSS} / \mathrm{E}$, violations caused by heavily loaded contingencies are obtained via PV and QV analyses. The results obtained for weak load buses from PV and QV analyses shows a strong agreement with the results obtained using the LQP_LT index. This proves that the LQP_LT index does not only provide accurate weak load bus detection, but also a fast solution as compared to using the PSS/E simulation. In conclusion, the LQP_LT tracing index is found to be robust, efficient and need less computation time as compared to the execution of voltage stability analysis using the PSS/E tool.

\section{ACKNOWLEDGEMENT}

The author would like to thank Universiti Tenaga Nasional for its support in funding the project under UNIIG 2017.

\section{REFERENCES}

[1] Pourbeik P, Kundur P. S., \& Taylor, C. W. The Anatomy of a Power Grid Blackout Root Causes and Dynamics of Recent Major Blackouts. Power and Energy Magazine (IEEE). 2006; 4(5): 22-29.

[2] Berizzi A. The Italian 2003 Blackout. IEEE Power Engineering Society General Meeting. 2004; 1673-1679.

[3] Corsi S, Sabelli C. General Blackout in Italy Sunday September 28, 2003. Power Engineering Society General Meeting (IEEE). 2004; 1691-1702.

[4] Glavic M, Novosel D, Heredia E, Kosterev D, Salazar A, Habibi Ashrafi A, Donnelly M. See it fast to keep calm: Real-Time Voltage Control under Stressed Conditions. IEEE Power Energy Mag. 2012; 10(4): 43-55.

[5] Vu K., Begovi'c M, Novosel D, Saha M. Use of Local Measurements to Estimate Voltage Stability Margin. IEEE Transactions on Power Syst. 1999; 14(3): 1029-1035.

[6] Smon I, Verbic G, Gubina F. Local voltage stability index using Tellegen's Theorem. IEEE Transactions on Power Systems. 2007; 21(3): 1267-1275.

[7] Nizam M, Mohamed A, Hussain A. Dynamic voltage collapse prediction in power systems using power transfer stability index. Proceedings of the International Power and Energy Conference. 2006; 246 - 250.

[8] Yang Wanga, Wenyuan Li, Jiping Lua. A New Node Voltage Stability Index based on Local Voltage Phasors. Elsevier Electric Power Systems Research. 2009; 79: 265-27.

[9] Kataoka Y, Watanabe M, Iwamoto S. A New Voltage Stability Index Considering Voltage Limit. Proceeding PSCE'06 IEEE. 2006; 1878-1883.

[10] Musirin I, Rahman T. K. A. Novel Fast Voltage Stability Index (FVSI) for Voltage Stability Analysis in Power Transmission System. Proceedings Student Conference on Research and Development: 265-268.

[11] Christie R. Power system test archive. 1993. 14 Bus power flow test case. https://www2.ee.washington.edu/research/pstca/pf14/pg_tca14bus.htm, Accessed on 20 August 2016.

[12] Verayiah R, Mohamed A, Shareef H. Assessment of Critical Loads Instigating Voltage Instability in Transmission Network using Novel Load Tracing Capable Index LQP_LT and PSS/E Tool Validation. Journal of Electrical Systems (JES). 2016; 12: 826-838.

[13] Verayiah R, Mohamed A, Shareef H, Abidin I.H.Z. Modified Novel Line Stability Factor Index with Reactive Power Tracing for Identification of Vulnerable Buses in Power System. Applied Mechanics and Materials, Trans Tech Publications. 2015; 785: 398-402.

[14] Verayiah R, Mohamed A, Shareef H. New Strategy for Optimal Load Shedding Incorporating Power Tracing Index, Journal of Fundamental and Applied Sciences. 2018; 10(5): 372- 387.

[15] Nisar S, Abbas A, Chifon T, Joe S, Les P, Mike K, Steve M, Tom G. Under Voltage Load Shedding Guidelines. 1999. Technical Report by WECC. 